ELORE (ISSN 1456-3010), vol. $13-1 / 2006$.

Julkaisija: Suomen Kansantietouden Tutkijain Seura ry. Taitto: Outi Fingerroos.

[http://cc.joensuu.fi/ /oristi/1_06/fin1_06.pdf]

\title{
PÄÄKIRJOITUS:
}

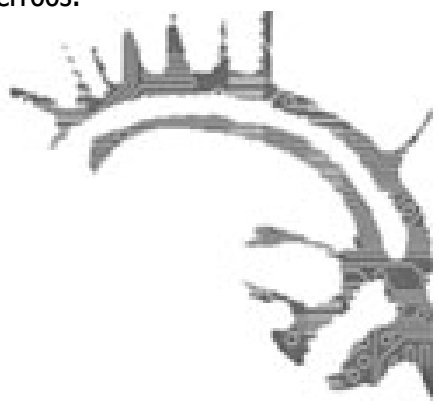

\section{HEDELMISTÄÄN PUU TUNNETAAN}

Outi Fingerroos

Nothing lasts forever - mikään ei ole ikuista! Elore, tarkemmin Suomen Kansantietouden Tutkijain Seura ry (SKTS), pääsi Tieteellisten seurain valtuuskunnan (TSV) julkaisutuelle uudessa rahanjaossa. TSV siis otti ensi metreillä sen innovatiivisen askeleen, jota Suomen Akatemialta odotettiin vuosia. Samalla Ilkka Niiniluodon alkuvuodesta 2005 esittämä visio on toteutumassa: tieteellisille seuroille osoitetun tuen jakoperiaate on uusiutumassa open access -myönteisemmäksi (Niiniluoto 2005: Tieteellinen julkaisutoiminta murroksessa. - Tieteessä tapabtuи 22(4)). TSV:lle kuuluu suurkiitos: Rohkea päätös, jota OA-julkaisijoiden ja kulttuurien tutkijoiden piirissä arvostetaan kenties forever!

Elore on saamastaan tuesta tietenkin ylpeä. Paukuttelimme henkseleitämme muutaman päivän, jonka jälkeen pysähdyimme pohtimaan tuen merkitystä ja suunnittelemaan tulevaa. Voimme panostaa verkkojulkaisemisen edistämiseen, vaikka ottamamme askeleet kuulostavat lopulta aika yksinkertaisilta: palkkaamme osa-aikaisen toimitussihteerin ja teemme kotisivuille teknisiä uudistuksia. Nuukasti kun elämme, koko toimituskunta voi kokoontua kaksi kertaa vuodessa luotaamaan tekemisiään eteenpäin. Päämäärämme on olla tuen arvoinen hyvän tiedon omenapuu jatkossakin.

\section{TAUSTAA ELEKTROLORISMILLE}

Jyrki Pöysä kirjoitti kaikkien aikojen ensimmäiseen Elektroloristiin 1/1994 tekstin

"Taustaa elektrolorismille", jossa hän tarjoili käyttöohjeen uudelle lehdelle:

[..] Lebden tulevaisuus on avoin ja rïppuu läbinnä sen vastaanotosta folkloristien ja folk.loristiikasta kiinnostuneiden piirissä. Tässä muodossa kokoon saatettuna lehden toimittaminen oli suorastaan yllättävän helppo tebtävä, kiïtos auliiden kirjoittajien sekä sen, että kirjoitusten sisältöo on jätetty kirjoittajien omalle vastuulle. 


\section{OUtI FingerRoOS}

Elektroloristin varhaisimmat juuret ulottuvat kerrostumiin, joibin oma muistini ei yllä. Lehden julkaisija, Kansantietouden tutkijoiden outo seura (per. 1937) toimitti jatkosodan varjossa Mitteilungen des Vereins fürfinnische Volkskunde lebteä, johon kirjoittivat sellaiset suuruudet kuin Albert Hämäläinen, Väinö Salminen, V.J. Mansikeka, A. V. Rantasalo, V. Tarkiainen, Väinö Kaukonen, T. I. Itkonen ja Jouko Hautala.

Ajatus omasta julkeaisutoiminnasta on elähdyttänyt myös myöhempiä kansantietouden tutkijoiden sukupolvia. Yhdistys on kaivettu esïn pöytälaatikon perukoilta ainakin kabdesti: 70-luvun alussa ja jälleen 90-luvun alussa. Toistuvat perääntymiset tieteen eturintamasta näyttävät jotenkin kuuluneen yhdistyksen elämänkaareen.

Lebden unsin historia on alle vuoden mittainen. Sïhen näbden, että nykyinen aika on täynnä kaikenkarvaista bittiviestintää ja säbköpostilebtiäkein syntyy kuin sieniä sateella, on ehkä täysin merkityksetön ykesityiskohta se, kun viime keväänä Joensunn yliopiston kirjaston untuuskirjahyllystä löysin Postmodern Culture lehden kirjoituksista kootun kirjan, ibmettelin sen sisältöä ja innostuin ajatuksesta varastaa lehden julkeaisuidea folk.loristien kä̈ttöön. Erilaisia tiedottamisen ja keskustelukanavan vaibtoehtoja oli Joensumn perinteentutkijoiden parissa jo pohdiskeltukin, mutta konkreettiset suunnitelmat hävisivät jonnekin vastaan ja puolesta argumenttien sekaan. Pienoinen yllätys olikin, miten byvin ajatus säbköpostilebdestä sitten otti tuulta alleen kun se kerran oli levinnyt tieteenalan mainiosti toimivaan sulliseen internettiin. Lehti siis oli tehtävä, vaikka ainakaan allekirjoittaneella ei ollut hajuakaan siitä, miten homma käytännössä tapabtuisi. Viime kädessä lehden toteutumisesta vastaakin sitä kobtaan osoitettu suopea kiinnostus. Vähäisin syy kiinnostukseen ei varmasti ole se, että kyseessä on nimenomaan sähköpostilehti. Lehteä julkaisevan seuran kannalta on olennaista, että tällainen julkeaisutapa on lähestulkoon ilmainen.

On kiinnostavaa, että Pöysän tekstissä paalutetaan lehtemme tätä päivää. Elore kuuluu ensimmäisiin Suomessa julkaistuihin OA-lehtiin, ja vuonna 1994 tulevaisuus oli täysin avoin. "Sähköpostilehti" onnistui vakiinnuttamaan paikkansa tiedejulkaisemisen alueella, josta ei 1990-luvulla "ollut hajuakaan".

1990-luvun alun innovatiivisesta kokeiluhengestä on edetty tiukkaan toimittamiseen. Tärkein Elorea julkaisevan SKTS:n oivallus lienee juuri vapaa saatavuus. Vuosien varrella se on kannustanut lähes kaikkia alamme asiantuntijoita kirjoittamaan lehteen niin artikkeleita, kolumneja, katsauksia kuin kirja-arvioita ja ajankohtaistekstejä. Itse asiassa Elore on ollut kirjoittamassa suomalaista OA-historiaa yhtenä ensimmäisistä tieteellisistä aikakausjulkaisuista, ja lehteämme onkin toistuvasti käytetty esimerkkinä vanhasta ja kokeneesta vapaan saatavuuden tiedejulkaisusta. Tämä on tuonut Elorelle paljon uusia lukijoita, mikä on eduksi koko tieteenalalle. 


\section{SKTS:N UUTISIA}

Suomen Kansantietouden Tutkijain Seuran vuosikokous pidettiin 22. maaliskuuta Joensuun perinnearkistossa. Vuosikokouksessa seuralle kutsuttiin 10 uutta jäsentä ja valittiin johtokunta. Uutena esimiehenä toimii FT Tarja Kupiainen, ensimmäisenä varaesimiehenä FT Tuulikki Kurki ja toisena varaesimiehenä FL Sari TuuvaHongisto. Sihteerinä aloittaa FM Taija Kaarlenkaski ja johtokuntaan kuuluvat FL Kirsi Laurén, FL Elina Makkonen, FM Erkki Matikainen ja rahastonhoitaja FM Jukka Timonen. Julkaisusihteeriksi valittiin FT Johanna Uotinen.

Seuran Kultaneito-sarjassa on ilmestynyt kuudes kirja, Sari TuuvaHongiston, Noora Talsin ja Johanna Uotisen toimittama Hei ihmistä varten! Teknologia, kansalaislähtöisyys ja arki. Kirjan voi ostaa 15 eurolla julkaisusihteeriltä; seuran jäsenille se postitettiin jäsenkirjeen mukana. Loppuvuodesta sarjassa ilmestyy jopa kaksi muuta kirjaa.

SKTS:n toiminta jatkuu aktiivisena. Seuran ensimmäinen kevätkoulu "Tutkimuksen nykyaika" järjestetään Helsingissä 12. toukokuuta. Kevätkoulusta on tarkoitus tehdä jokavuotinen perinne. Ensimmäisen tapaamisen ohjelmaan voit tutustua seuran kotisivuilla osoitteessa $<$ http://cc.joensuu.fi/ loristi/skts/>. Syyspuolella seuran linja-auto suuntaa käsivarren Lappiin, ja kekrin aikaan toteutetaan populaarikulttuurin ilta Joensuussa. Näistä tapahtumista tiedotetaan tarkemmin sähköpostilistalla ja kotisivujen ajankohtaisissa.

\section{ELORE 1/2006}

Kevään 2006 teemanumero The Oral History Network in The Nordic and Baltic Context on ensimmäinen kansainvälinen numero lehtemme historiassa. Juuri TSV:n julkaisutuki mahdollisti sen toimittamisen, sillä lehdellämme ei ole ollut aiemmin varaa artikkelien kielentarkastuksiin. Mukana on tekstejä Latviasta, Suomesta, Venäjältä ja Virosta.

Teemanumerossa kokeilimme ensimmäistä kertaa artikkelien jakoa referoituihin ja katsaustyyppisiin artikkeleihin (review articles). Jako todennäköisesti otetaan Eloressa pysyvästi käyttöön. Tämä on keino tarjota julkaisuväylä sellaisille teksteille, jotka eivät täytä kaikkia artikkeleille asetettuja kriteereitä mutta vievät tieteellistä keskustelua kuitenkin eteenpäin. Lisäksi kevään numerossa on muhkea tarjonta lectioita ja seminaariraportteja sekä kokonaiset 20 kirja-arvioita. Elore onkin saavuttamassa tavoitettaan julkaista arvio kaikista tärkeimmistä alamme uusista kirjoista.

Elore 1/2006 on valmiina tutustumista varten. Lämmin kiitos kaikille kirjoittajille ja toimittajille! Syksyn numero 2/2006 on teemasta vapaa, joten olkaa yhteyksissä päätoimittajaan ja eri osioiden vastuutoimittajiin. Kirjoitusohjeet löydätte Eloren kotisivuilta. Kevään 2007 teemanumeron aihetta emme ole vielä päättäneet, joten otamme ilolla vastaan lukijoiden ideat - teemanumeron toimittajat voivat olla Eloren toimituskunnan ulkopuoleltakin! 